\title{
Encefalomielitis aguda diseminada en el adulto \\ Caso de asociación con infección por el virus de la hepatitis A
}

\section{Acute disseminated encephalomyelitis in adults Association with infection by hepatitis A virus}

\author{
José Ignacio Valenzuela, Jesús Rodríguez, Rodolfo Dennis, \\ Danny Novoa, Edgar Barrera, Carmen Cec ilia Gómez \\ - Bogotá, D.C (Colombia)
}

\section{Resumen}

La encefalomielitis aguda diseminada (ADEM) es una enfermedad desmielinizante monofásica, que usualmente sigue a una infección o vacunación, principalmente por el virus del sarampión, y ocurre principalmente en niños y adultos jóvenes. Su asociación con la infección por el virus de la hepatitis A es rara, y se halla poco documentada. Se presenta el caso de una paciente femenina de 53 años con ADEM e infección por hepatitis A. Se resalta la inclusión de la hepatitis A dentro del tamiz causal de pacientes adultos con ADEM. (Acta Med Colomb 2014; 39: 64-68)

Palabras clave: encefalomielitis aguda diseminada, hepatitis A, síndrome de Guilläin Barré.

\begin{abstract}
Acute disseminated encephalomyelitis (ADEM) is a monophasic demyelinating disease that usually follows an infection or vaccination, mainly by the measles virus and occurring primarily in children and young adults. His association with infection by hepatitis A virus is rare, and is poorly documented. The case of a 53 years old female patient with ADEM and infection by hepatitis A is presented. The inclusion of hepatitis A within the causal screening of adult patients with ADEM is highlighted. (Acta Med Colomb 2014; 39: 64-68).
\end{abstract}

Keywords: acute disseminated encephalomyelitis, hepatitis A, Guilläin-Barre syndrome.
Dr. José Ignacio Valenzuela: Residente de Medicina Interna, Universidad del Rosario; Dr. Jesús Rodríguez: Departamento de Neurología, Fundación Cardioinfantil; Dres. Rodolfo Dennis, Danny Novoa, Edgar Barrera, Carmen Cecilia Gómez: Departamento de Medicina Interna, FundaciónCardioinfantil. Bogotá, D.C. (Colombia). Correspondencia. Dr. José Ignacio Valenzuela. Bogotá, D.C. (Colombia).

E-mail: joseival@gmail.com

Recibido: 10/XI/2012 Aceptado: 16/X/2013

\section{Introducción}

La encefalomielitis aguda diseminada (ADEM, del inglés Acute Disseminated Encephalomyelitis) es una condición desmielinizante aguda, que afecta principalmente el cerebro y la médula espinal. Usualmente sigue a una infección o vacunación y se caracteriza en las neuroimágenes por lesiones multifocales de la sustancia blanca. Se considera como una enfermedad monofásica, aunque en raras ocasiones puede cursar con recaídas, caso en el cual se le denomina como ADEM multifásico (Tabla 1) (1).

$\mathrm{Su}$ incidencia exacta es desconocida. Anteriormente, se asociaba con infecciones virales de la infancia como el sarampión y la varicela, entre otras, con alta morbimortalidad. Hoy en día, tras el avance en las técnicas de vacunación y las estrategias para el control de enfermedades infecciosas, la asociación con este tipo de enfermedades inmunoprevenibles es menos clara, y ocurre más bien siguiendo infecciones respiratorias altas, usualmente de tipo viral, aunque el agente etiológico específico se desconoce (1).

Otra variante etiológica de ADEM es aquella relacionada con la vacunación, conocida como "encefalitis posinmunización", la cual es indistinguible clínicamente de la variante infecciosa arriba descrita, excepto porque la

Tabla 1. ADEM y desórdenes asociados

\begin{tabular}{|l|l|}
\hline Encefalomielitis aguda diseminada & $\begin{array}{l}\text { Posinfecciosa } \\
\text { Posinmunización }\end{array}$ \\
\hline Leucoencefalitis aguda hemorrágica & $\begin{array}{l}\text { Mielitis transversa } \\
\text { Neuritis óptica } \\
\text { Cerebelitis } \\
\text { Encefalitis del tallo }\end{array}$ \\
\hline forma aguda restringida & \\
\hline $\begin{array}{l}\text { Desórdenes desmielinizantes inflamatorios } \\
\text { agudos, forma multifásica, y esclerosis múltiple }\end{array}$ & \\
\hline
\end{tabular}


Tabla 2. Variantes infecciosas asociadas con ADEM.

\begin{tabular}{|c|c|}
\hline Infecciones & $\begin{array}{l}\text { Virales } \\
\text { - Sarampión } \\
\text { - Paperas } \\
\text { - Influenza A o B } \\
\text { - Hepatitis A o B } \\
\text { - Herpes simplex } \\
\text { - Herpes humano virus E } \\
\text { - Varicela, rubéola } \\
\text { - Virus de Epstein Barr } \\
\text { - Citomegalovirus } \\
\text { - VIH } \\
\text { Otros } \\
\text { - Mycoplasma pneumoniae. } \\
\text { - Chlamydia. } \\
\text { - Legionella. } \\
\text { - Campylobacter. } \\
\text { - Streptococcus }\end{array}$ \\
\hline Vacunas & $\begin{array}{l}\text { Rabia } \\
\text { Difteria, tétanos, pertussis } \\
\text { Varicela } \\
\text { Encefalitis japonesa B } \\
\text { Polio. } \\
\text { Hepatitis B. } \\
\text { Influenza. }\end{array}$ \\
\hline
\end{tabular}

primera usualmente involucra con mayor preponderancia el sistema nervioso periférico. La mayor asociación de esta variante ocurre con la vacuna triple viral (MMR - Measles, Mumps, Rubella), con una incidencia de 1-2 por millón de vacunas con virus vivo atenuado. No obstante, el riesgo de ocurrencia de ADEM posinmunización es 20 veces menor que la variante posinfecciosa; adicionalmente, con la elaboración de nuevas vacunas sin base en tejido neural, la encefalitis posinmunización cada vez es menos frecuente (Tabla 2) (2).

Aunque se encuentra descrita en la literatura $(1,7)$, la asociación de ADEM con infección por virus de hepatitis A es poco frecuente. Hay algunos casos aislados descritos en niños (8-11), pero hasta donde sabemos, sólo dos casos reportados en adultos (12). Presentamos aquí un caso visto en nuestro centro.

\section{Presentación del caso}

Paciente femenina de 53 años, mestiza, natural de Guatavita y procedente de Zipaquirá (Cundinamarca); ingresó a la institución por cuadro de cinco días de aparición súbita de parestesias en la cara dorsal del primer dedo de la mano derecha, que se extendieron a toda la mano en cuestión de horas, y posteriormente parestesias distales en los dedos de ambos pies. Al cabo de 24 horas, debilidad en manos evidenciada por incapacidad para la prensión y movimientos finos. Refería haber presentado la semana previa y de un día evolución, cuadro diarreico sin signos de alarma que se autolimitó. Como único antecedente de importancia, presentaba hipotiroidismo en suplencia hormonal.
Al examen físico se encontró paciente en regulares condiciones generales, afebril, con signos vitales normales. Consciente, orientada, con paresia distal de 4/5 en manos con imposibilidad para realizar pinza, y en miembros inferiores una paresia distal 4/5 con leve dificultad para la plantiextensión; adicionalmente, arreflexia rotuliana y aquiliana e hiporreflexia +/++++ en miembros superiores; al examen de sensibilidad, cursaba con sensación de parestesias y disestesias en las cuatro extremidades, sin nivel sensitivo.

Se solicitaron paraclínicos de ingreso que incluyeron un hemograma con leve leucocitosis y diferencial normal, VSG ligeramente aumentada. TAC cerebral simple normal seguida por resonancia magnética con contraste y difusión que evidenció pequeñas lesiones focales inespecíficas de sustancia blanca difusas (Figura 1).

Durante la hospitalización, la paciente presentó ictericia mucocutánea, para lo cual se solicitó perfil hepático que mostró hiperbilirrubinemia indirecta con transaminasas y resto de estudios normales. Se descartó hemólisis. Se tomó una ecografía abdominal, que fue normal.

La paciente continuó con sintomatología neurológica dada por aumento de las parestesias, en patrón de bota y guante. Neuroconducciones, electromiografía y onda $f$ de cuatro extremidades compatible con polineuropatía axonal motora y sensitiva aguda, sin compromiso mielínico, a lo que se le dio interpretación inicial de síndrome de Guilläin Barré variante axonal motora y sensitiva (AMSAN) con progresión clínica, y se inició manejo con inmunoglobulina $\mathrm{G}$ intravenosa a razón de a $0.4 \mathrm{~g} / \mathrm{Kg} /$ día en la unidad de cuidado intensivo. Adicionalmente, se descartó infección por VIH.

Al quinto día de tratamiento presentó episodio convulsivo tonicoclónico generalizado, presumiblemente como complicación asociada con el tratamiento. Se tomó nueva RMN cerebral que mostró la aparición de múltiples lesiones comprometiendo la sustancia blanca subcortical frontoparietal bilateral, hiperintensas en T2 y Flair, sin realce con el gadolinio, compatible con ADEM, posterior a lo cual se inició manejo con corticoide intravenoso.

Un perfil hepático de control mostró elevación de las transaminasas en un factor de 5. Se solicitó panel viral hepático que resultó compatible con infección por el virus de la hepatitis A (IgM > 400). Se decidió posteriormente solicitar RM de columna cervical y torácica para descartar lesiones desmielinizantes medulares, que resultó normal, y videotelemetría de tres horas por cambios alternantes del estado de conciencia asociado al antecedente reciente de crisis convulsiva, la cual no mostró descargas epileptiformes. Posteriormente, la paciente fue dada de alta y evolucionó satisfactoriamente, con remisión completa de los hallazgos neurológicos.

\section{Discusión}

Usualmente, la ocurrencia de ADEM ha sido asociada con infección por el virus del sarampión, con una frecuencia aproximada de uno en 1000 casos, seguida por varicela 


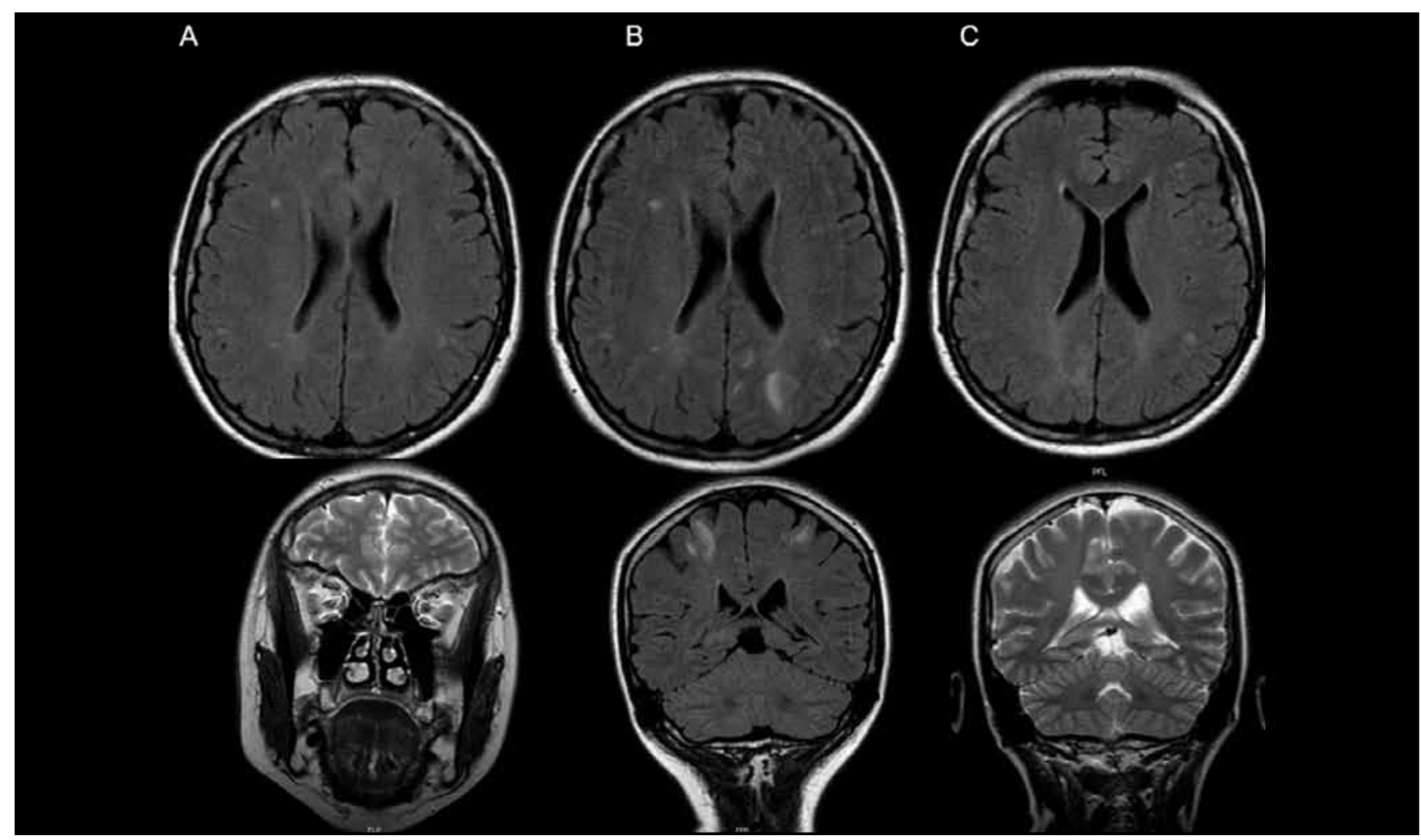

Figura 1. Evolución imagenológica de la paciente: A) RMN cerebral (secuencia FLAIR) que evidenció pequeñas lesiones focales inespecíficas de sustancia blanca; B) RMN cerebral tomada cinco días después, con aumento y aparición de múltiples lesiones que comprometen la sustancia blanca subcortical frontoparietal bilateral, hiperintensas, sin realce con el gadolinio, de aspecto inespecífico, compatible con ADEM; C) RMN cerebral control 10 días después que mostró mejoría de las lesiones hiperintensas de la sustancia blanca bilateral diseminadas, observando disminución del tamaño tras el tratamiento, aunque con persistencia de lesiones en la unión occipitoparietal bilatetal corticosubcorticales.

zóster y rubéola, con incidencias de uno en 10000 y uno en 20000, respectivamente. Otras infecciones precipitantes de tipo no viral incluyen el Mycoplasma pneumoniae y otros gérmenes atípicos causantes de infecciones respiratorias (7).

Por su parte, la encefalopatía posinmunización, causante de los denominados accidentes neuroparalíticos, históricamente se ha asociado principalmente con la vacuna contra la rabia, cuando se producía el inóculo a partir de una preparación de médula espinal de conejo infectada con el virus. Con el desarrollo de vacunas no derivadas de tejido nervioso infectado, se ha visto una disminución marcada de la frecuencia de estos eventos adversos. Actualmente, las nuevas vacunas contra sarampión, paperas y rubéola (MMR - triple viral) son las más asociadas con ADEM posinmunización; su incidencia es de uno a dos casos por millón de vacunas con virus vivo atenuado administradas. Esta incidencia es mucho menor a aquella relacionada con la infección por el virus del sarampión.

En cuanto a la fisiopatología, la evidencia disponible sugiere que ADEM resulta de una respuesta autoinmune transitoria contra la mielina $\mathrm{u}$ otros autoantígenos como consecuencia de reacción cruzada por imitación molecular de los antígenos virales dada su similitud con los propios, o bien por activación no específica clonal de células $\mathrm{T}$ autorreactivas. Ésto, probablemente facilitado por cierta susceptibilidad genética asociada con genes polimórficos del complejo mayor de histocompatibilidad (CMH) y no asociados con éste, incluyendo aquellos que codifican para moléculas efectoras (citoquinas, quemoquinas) o receptores del sistema inmune; de especial relevancia, se cuentan los genes clase II codificantes para el antígeno leucocitario humano (3).

La leucoencefalitis aguda hemorrágica constituye una variante severa y usualmente fatal de ADEM. Sus características patológicas incluyen una vasculitis necrosante de las vénulas. Otra variante, la encefalomielitis hiperaguda alérgica experimental corresponde a un trastorno de tipo autoinmune desencadenado experimentalmente tras la exposición a antígeno mielínico como la proteína básica de la mielina, la proteína proteolipídica y la glicoproteína oligodendrocitaria mielínica.

Clínicamente, ADEM se manifiesta con síntomas sistémicos como fiebre, astenia, adinamia, mialgias, cefalea, náusea, vómito, que preceden con un intervalo de cuatro a 21 días los síntomas neurológicos focales o multifocales, los cuales constituyen la piedra angular de la enfermedad e incluyen el desarrollo de encefalopatía (desde letargo hasta coma), hemiparesia, parálisis de nervios craneales y paraparesia. Otros hallazgos menos frecuentes incluyen meningismo, ataxia y diversos desórdenes del movimiento. Pueden incluso ocurrir 
convulsiones, especialmente en los casos severos y la forma aguda hemorrágica. Cuando ocurre, la neuritis óptica es por lo general bilateral y la mielopatía transversa, completa (4). La recuperación es a menudo completa (50\% de los casos) y ocurre al término de semanas a meses. La mortalidad llega a alcanzar sin embargo, hasta $30 \%$.

ADEM ocurre principalmente en niños y adultos jóvenes, siendo su presentación clínica en todos los rangos de edad similar no obstante, en los adultos parece asociarse menos frecuentemente con fiebre, cefalea y meningismo, y más con déficits sensitivos. La neuritis óptica es también infrecuente en las personas mayores.

En los hallazgos paraclínicos, el análisis de líquido cefalorraquídeo (LCR) puede ser normal, aunque típicamente se asocia con una presión de apertura incrementada, pleocitosis linfocítica (hasta 1000 células $/ \mathrm{mm}^{3}$ ) e incremento de las proteínas (usualmente $<1 \mathrm{mg} / \mathrm{L}$ ). Puede haber, además, niveles aumentados de gammaglobulina y de proteína básica mielínica. El contenido de glucosa es normal. Adicionalmente, es posible que curse con anomalías electroencefalográficas, aunque usualmente son inespecíficas y son probablemente las neuroimágenes las que mayor valor aportan en el diagnóstico.

La tomografía computadorizada (TAC) cerebral es generalmente normal al inicio de los síntomas, apareciendo los hallazgos hacia los cinco a 14 días, que corresponden a lesiones multifocales de baja atenuación en la sustancia blanca subcortical. Por su parte, los cambios en la resonancia magnética (RMN) cerebral ocurren tempranamente, y esta técnica diagnóstica ofrece una mejor visualización de las lesiones desmielinizantes, las cuales, característicamente corresponden a áreas parcheadas con aumento de la intensidad de la señal en T2 y FLAIR, sin efecto de masa, pero con edema perifocal importante. De resaltar, constituye un criterio sine qua non el hecho de que las lesiones deben tener la misma antigüedad y no deben aparecer nuevas lesiones después del ataque inicial. Ésto, además de la ausencia de involucramiento del cuerpo calloso, lo diferencian de la esclerosis múltiple (EM), que constituye uno de los principales diagnósticos diferenciales (Tabla 3). Por otro lado, mientras que el compromiso talámico es excepcional en la EM, puede aparecer hasta en $40 \%$ de los casos de ADEM. Aunque ADEM es típicamente un proceso diseminado del sistema nervioso central (SNC), en algunos casos prima la patología medular. La neuromielitis óptica (enfermedad de Devic) puede ser causada por ADEM o bien, por lupus eritematoso sistémico y puede complicar el trabajo diagnóstico. Aunque la enfermedad cerebrovascular (ECV) constituye la principal complicación del síndrome antifosfolípido, se ha descrito asociación con mielitis transversa y neuritis óptica (incluyendo Devic), imitando los hallazgos imagenológicos de ADEM.

En cuanto al tratamiento, se enfoca en suprimir una supuesta alteración de la respuesta inmune a un agente infeccioso o posinmunización. El uso de corticoides
Tabla 3. Causas de áreas parcheadas de intensidad de señal aumentada en T2 (RMN).

\begin{tabular}{|ll|}
\hline - Esclerosis múltiple & Encefalopatía por VIH \\
- Vasculitis & - $\begin{array}{l}\text { Panencefalitis esclerosante } \\
\text { subaguda }\end{array}$ \\
$\begin{array}{l}\text { reversible } \\
\text { - Eclampsia }\end{array}$ & Encefalopatía mitocondrial \\
- Leucoencefalopatía & Leucodistrofias \\
arteriosclerótica subcortical & Encefalopatías tóxicas \\
- $\begin{array}{l}\text { Leurosarcoidosis } \\
\text { progresiva multifocal }\end{array}$ & Mielinolisis osmótica \\
& \\
\hline
\end{tabular}

intravenosos y hormona adenocorticotrópica han mostrado mejorías en los desenlaces. En casos de fallo a la respuesta con corticoides, una segunda línea es la plasmaféresis (5) o la inmunoglobulina intravenosa (IVIG) (6). En algunos casos, se han utilizado agentes citotóxicos con éxito. Por otro lado, se ha sugerido que la terapia antibiótica, oportunamente implementada, podría limitar la respuesta inmune neurotóxica en los casos de ADEM asociados a infección. No obstante, en la actualidad se carece de tratamientos efectivos contra muchos de los virus implicados en ADEM.

Las manifestaciones extrahepáticas de la infección por hepatitis A no son frecuentes. Aunque constituye un picornavirus que puede infectar el SNC, en ausencia de insuficiencia hepática severa, las manifestaciones neurológicas son excepcionales. No obstante, se han reportado algunos casos de meningoencefalitis, encefalitis, mielitis transversa y neuritis óptica (12). Más aún, la proteína estructural VP3 del virus de la hepatitis A comparte 7 tripéptidos comunes con la proteína básica de la mielina, lo cual podría desencadenar una enfermedad desmielinizante sobre la base de imitación molecular entre antígenos viral y proteínas del huésped.

Nuestra revisión de la literatura sólo mostró dos casos reportados en adultos (12). El primero se trataba de un paciente de 29 años sin antecedentes neurológicos quien desarrolló fiebre, cefalea, alteración para la marcha y retención urinaria. Los paraclínicos evidenciaron transaminitis (ALT $1555 \mathrm{UI} / \mathrm{L}, \mathrm{AST} 540 \mathrm{UI} / \mathrm{L}$ ) y título elevado de anticuerpos IgM contra el virus de la hepatitis A. En los días subsiguientes, el paciente desarrolló ataxia severa de la marcha, signos piramidales bilaterales de miembros inferiores e hipoestesia con un nivel sensorial T10. El estudio de líquido cefalorraquídeo (LCR) fue normal y la inmunofijación con anti-IgG demostró la misma banda en la región catódica de gammaglobulinas en sangre y LCR. Se descartó infección por hepatitis $\mathrm{B}$, hepatitis $\mathrm{C}$, citomegalovirus, herpes simplex, varicela zóster y Borrelia burgdorferi, así como coxsackievirus tipo 4, 9, B1-6, ECHO virus tipos 2, 4, 6, 8, 9,11 y poliovirus tipos 1,2 y 3 , Epstein-Barr virus, VIH y sífilis. Se confirmó la infección por hepatitis A mediante la 
documentación de anticuerpos específicos anti-HAV IgM e IgG en sangre, usando el inmunoensayo enzimático por micropartículas. Los hallazgos imagenológicos cerebrales fueron compatibles con ADEM. El paciente respondió al manejo con metilprednisolona intravenoso, sin presentar secuelas en el seguimiento a dos años.

El segundo fue un caso reportado de Marruecos, de un hombre de 44 años hospitalizado por tetraparesia piramidal, pérdida de sensibilidad propioceptiva y compromiso de pares craneanos. Concomitantemente, desarrolló ictericia y fatiga. Tanto el análisis del LCR como la RMN cerebral fueron normales, y los exámenes de laboratorio evidenciaron una elevación de transaminasas y niveles aumentados de $\operatorname{IgM}$ e IgG contra el virus de la hepatitis A. Tras el establecimiento del diagnóstico de ADEM, el paciente fue tratado con corticoide intravenoso a altas dosis y mantenimiento con cortidoide oral, presentando deterioro progresivo y posteriormente muerte ocho meses después (13).

Nuestro caso contribuye con la escasa evidencia disponible de la variante posinfecciosa de ADEM en el adulto, particularmente asociada con infección por hepatitis A. Nuestra paciente, a pesar de haber cursado con las características típicas de la enfermedad, especialmente desde el punto de vista imagenológico y de la respuesta a la terapéutica instaurada, tuvo un desencadenante no esperado. El presente trabajo resalta la importancia, sobre la base de una evidencia más robusta, de tamizar para el virus de la hepatitis A como potencial factor causal de ADEM.

\section{Referencias}

1. RK, Garg. Acute disseminated encephalomyelitis. Postgrad Med J 2003; 79: 11-17.

2. Murthy JM, Yangala R, Meena AK, et al. Acute disseminated encephalomyelitis: clinical and MRI study from South India. J Neurol Sci 1999; 165: 133-8.

3. 't Hart BA, Brok HP, Amor S, et al. The major histocompatibility complex influences the ethiopathogenesis of MS-like disease in primates at multiple levels. Hum Immunol 2001; 62: 1371 - 81.

4. Stuve O,Zamvil SS. Pathogenesis, diagnosis and treatment of acute disseminated encephalomyelitis. Curr Opin Neurology 1999; 12: 395-401.

5. Kanter DS, Horensky D, Sperling RA, et al. Plasmapheresis in fulminant acute disseminated encephalomyelitis. Neurology 1995; 45: 824-7.

6. Marchioni E, Marinou-Aktipi K, Uggetti C, et al. Effectiveness of intravenous immunoglobulin treatment in adult patients with steroid resistant monophasic or recurrent acute disseminated encephalomyelitis. J Neurol 2002; 249: 100-4.

7. Bennetto L, Scolding N. Inflammatory/post-infectious encephalomyelitis. $J$ Neurol Neurosurg Psychiatry 2004; 75: i22-i28.

8. Alehan FK, Kahveci S, Uslu Y, YildirimT, Yilmaz B. Acute disseminated encephalomyelitis associated with hepatitis A virus infection. Ann Trop Paediatr 2004; 24: 141-4.

9. Oleszak EL, Lin WL, Legido A, MelvinJ, Hardison H, Hoffman BE,Katsetos CD, Platsoucas CD. Presence of oligoclonal T cells in cerebrospinal fluid of a child with multiphasic disseminated encephalomyelitis following hepatitis A virus infection. Clin Diagn 2001; 8: 984-92.

10. Tan H, Kilicaslan B, Onbas O, Buyukavci M. Acute disseminated encephalomyelitis following hepatitis A virus infection. Pediatr Neurol 2004; 30: 207-209.

11. Unay B, Sarici SU, Bulakbasi N, Akin R, Gokcay E. Intravenous immunoglobulin encephalomyelitis associated with hepatitis A infection. Pediatr Int 2004; 46: 171-173.

12. Quaranta L, Batocchi AP, Sabatelli M, Nociti V, Tartaglione T, Cuonzo F, Tonallii PA. Monophasic demyelinating disease of the central nervous system associated with Hepatitis A infection. J Neurol 2006; 253: 944-945.

13. El Moutawakil B, Bourezgui M, Rafai MA, Sibai M, Boulaajaj FZ, Moutaouakil F, Otmani H, Slassi I. Acute disseminated encephalomyelitis associated with hepatitis A virus infection. Rev Neurol (Paris) 2008; 164: 852-4.

14. Bennetto L, Scolding N. Inflammatory/post-infectious encephalomyelitis. $J$ Neurol Neurosurg Psychiatry 2004; 75 Suppl 1:i22-8. 